\title{
Simulation and Analysis of Dynamic Characteristics for Power System with Large-scale Wind Power
}

\author{
Gu Bo, Hu Hejuan, Liu Tianxiao and Qiu Daoyin \\ School of Electric Power, North China University of Water Resources and \\ Electric Power, Zhengzhou, China, 450045 \\ gb19820915@163.com
}

\begin{abstract}
It is important significance to study the dynamic characteristics of power system with large-scale wind power, because large-scale wind power access to power system has a great influence on the stable operation of the power system. In this paper, the operation principles of wind turbines, hydropower units and thermal power units are analyzed respectively and the corresponding mathematical model are established. Based on these mathematical models, the multi-source hybrid electric power system model containing wind turbines, hydropower units and thermal power units is built up. The multi-source hybrid electric power system model is simulated and analyzed in the condition of wind speed fluctuation. Simulation results show that when the power output of wind turbines changes, the multi-source hybrid power system model can accurately describe the dynamic characteristics of power system.
\end{abstract}

Keywords: wind turbine; hydropower units; thermal power units; multi-source hybrid electric power system; dynamic characteristics

\section{Introduction}

The environmental pollution problems caused by fossil energy have become a major obstacle to the sustainable development strategy of national sources. Using non-pollution and renewable energy to replace fossil energy sources, is one of the future development trends of electric power [1-4]. Wind energy, as one of the renewable energy, with the advantages of cleaning and large storage capacity, has been widely developed and used. Because of the random uncertainty of wind power, when large-scale wind power is integrated into the power system, which brings some challenges to the power system stable operation. Therefore, the research on the dynamic characteristics of power system with large-scale wind power is of great significance to improve the development and utilization of wind power.

At present, for multi-source hybrid power system, scholars have done a lot of studies and made a certain achievements. Baghdadi et al. [5] established a hybrid power system with photovoltaic power, wind power and diesel power. The utilization efficiency of clean energy is improved by optimizing the proportion of photovoltaic power, wind power and diesel power in the hybrid power system. The study shows that $70 \%$ energy of the hybrid power system can be supplied by these renewable energy sources. Brandoni et al. [6] established a combined cooling heating and power(CCHP) system, which is composed of photovoltaic power and gas turbine power, and the corresponding energy optimization control strategy is proposed. The simulation results show that the CCHP system can reduce annual consumption of natural gas by $20 \%$ 30\%. In order to improve the efficiency of photovoltaic power, reduce the amount of carbon dioxide emissions and overcome the intermittent of photovoltaic power, Shah et al. [7] established a combined heat and power (CHP) hybrid system with photovoltaic power and energy storage. The CHP hybrid system is used to provide electricity and heat for households. The simulation 
results verify the feasibility of the system. Because of the stochastic nature of renewable energy, Khare et al. [8] presented a comprehensive review of the various aspects for hybrid renewable energy system (HRES).

In literature [9], a distributed generation system with wind-photovoltaic-biogas is constructed, and the stability and economy of the distributed generation system is improved by using the improved adaptive genetic algorithm to optimize the distributed generation system. A wind-photovoltaic-water hybrid power generation system is proposed in literature [10]. The simulation results show that the complementary characteristics of wind power, photovoltaic power and hydro power are significant, and the hybrid power generation system can solve the imbalance problem between electric energy production and consumption. In literature [11], a hybrid power system of windphotovoltaic-storage is proposed, and genetic algorithm is used to optimize the hybrid power system. The simulation and optimization results show that the hybrid power system can reduce harmful gas emissions. In order to study the operation characteristics of distributed power, the hybrid power generation system consisting of wind turbines, fuel cells and super capacitors is selected as research object, and the operation characteristics of the hybrid power generation system are studied. The simulation results show that the hybrid power generation system can use wind energy effectively, as well as track the load changes [12].

In the above content, the structure, the operation characteristics and optimal control of distributed generation system are studied, and some research results have been obtained. However, due to the diversity and complexity of multi-source hybrid power system, there are still a number of technical problems have not been solved. Especially, the study on the stability of power system with large-scale wind power is relatively few, which affects the further development and utilization of wind power.

Based on the existing research techniques, a power system model with large-scale wind power is established in this paper, and the operation characteristics of the system are simulated and analyzed. Firstly, the operation principles of wind turbines, hydraulic turbines and steam turbines are analyzed and the corresponding mathematical models are established. On this basis, considering the distribution characteristics in the spatial scale of wind turbines, hydropower units and thermal power units, the multi-source hybrid power system model containing these generator units is established. The dynamic characteristics of the multi-source hybrid power system are simulated and analyzed under the condition of wind speed change.

\section{Operation Principles of Wind Turbine}

Wind power is the processes of converting wind energy into mechanical energy, and then into electrical energy. Wind turbine is the most important part in wind power system, which is used to capture the kinetic energy carried by flowing air and convert it into mechanical energy. Therefore, wind turbine not only determines the power output of wind power system, but also directly affects the safety and stability of wind power system. Hence, wind turbine is the key component of wind power system.

According to the knowledge of aerodynamics, the kinetic energy carried by flowing air can be expressed as equation (1).

$$
P_{v}=\frac{1}{2}\left(\rho S_{\mathrm{b}} v\right) v^{2}=\frac{1}{2} \rho S_{\mathrm{b}} v^{3}
$$

In equation (1), ${ }^{v}$ represents air velocity; $\rho^{\rho}$ represents air density; ${ }^{\mathrm{b}}$ represents the blade swept area.

Because the wind energy passing through the rotor rotation surface is only partially absorbed. Therefore, the wind energy utilization coefficient $C_{\mathrm{p}}$ is used to characterize the 
ability of wind turbine to capture wind energy. The expression of $C_{\mathrm{p}}$ is shown as equation (2).

$$
C_{\mathrm{p}}=\frac{\text { Wind turbine power output }}{\text { Kinetic energy contained in air }}=\frac{P_{\mathrm{w}}}{P_{v}}
$$

Hence, the power output of wind turbine can be expressed as equation (3).

$$
P_{\mathrm{w}}=C_{\mathrm{p}} P_{v}=\frac{1}{2} \rho S_{\mathrm{b}} v^{3} C_{\mathrm{p}}=\frac{\pi}{8} \rho D_{\mathrm{r}}^{2} v^{3} C_{\mathrm{p}}
$$

In equation (3), $D_{\mathrm{r}}$ represents the diameter of rotor.

Wind energy utilization coefficient $C_{\mathrm{p}}$ is an important parameter to characterize the operation efficiency of wind turbine, which can be determined by tip speed ratio $\lambda$ and pitch angle $\beta$, and the calculation processes of tip speed ratio $\lambda$ is shown as equation (4).

$$
\lambda=R \omega / v
$$

Where, $R$ represents the radius of rotor; $\lambda$ represents the tip speed ratio; $\omega$ represents the angular velocity of blade rotation.

At present, variable pitch wind turbines are used commonly. The characteristics of variable pitch wind turbines are usually represented by a cluster of wind energy utilization coefficient, as shown in Figure 1. The wind energy utilization coefficient $C_{\mathrm{p}}$ can be expressed as a function of tip speed ratio $\lambda$ and pitch angle $\beta$, namely $C_{\mathrm{p}}(\beta, \lambda)$. The coupling relationship between $C_{\mathrm{p}}, \lambda$ and $\beta$ is shown as equations (5) and (6).

$$
C_{\mathrm{P}}(\beta, \lambda)=0.22\left(\frac{116}{\lambda_{i}}-0.4 \beta-5\right) e^{-\frac{22.5}{\lambda_{i}}}
$$

$$
\frac{1}{\lambda_{i}}=\frac{1}{\lambda+0.08 \beta}-\frac{0.035}{\beta^{3}+1}
$$

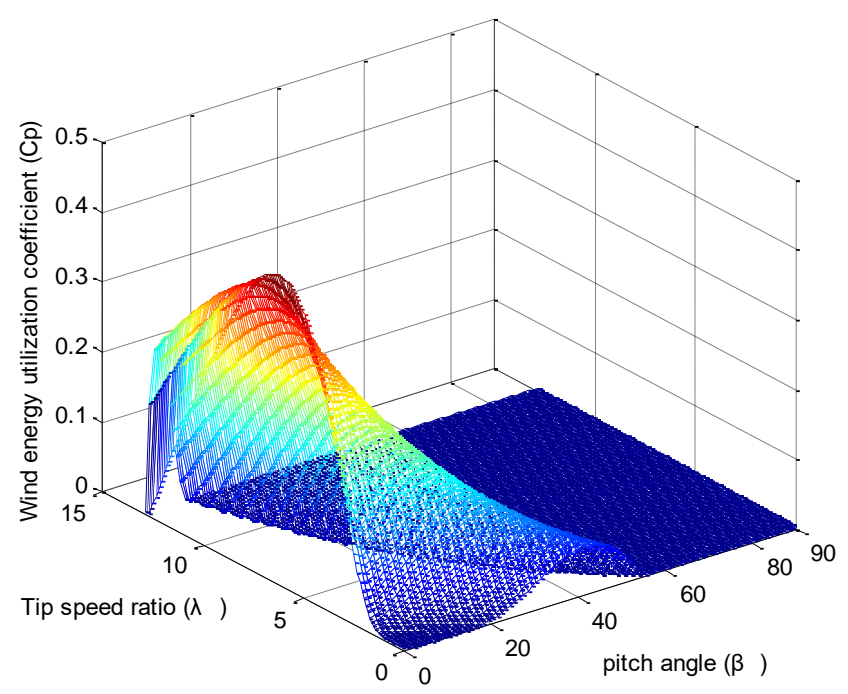

Figure 1. Coupling Relationship between $C_{\mathrm{p}}, \lambda$ and $\beta$ 
For the actual operation wind turbines, which mainly operate under the rated wind speed. When the wind turbines operate under the rated wind speed, the pitch angle is 0 degree, and the size of $C_{\mathrm{p}}$ is only related to $\lambda$, as shown in Figure 2.

\section{Operation Principles of Hydraulic Turbine}

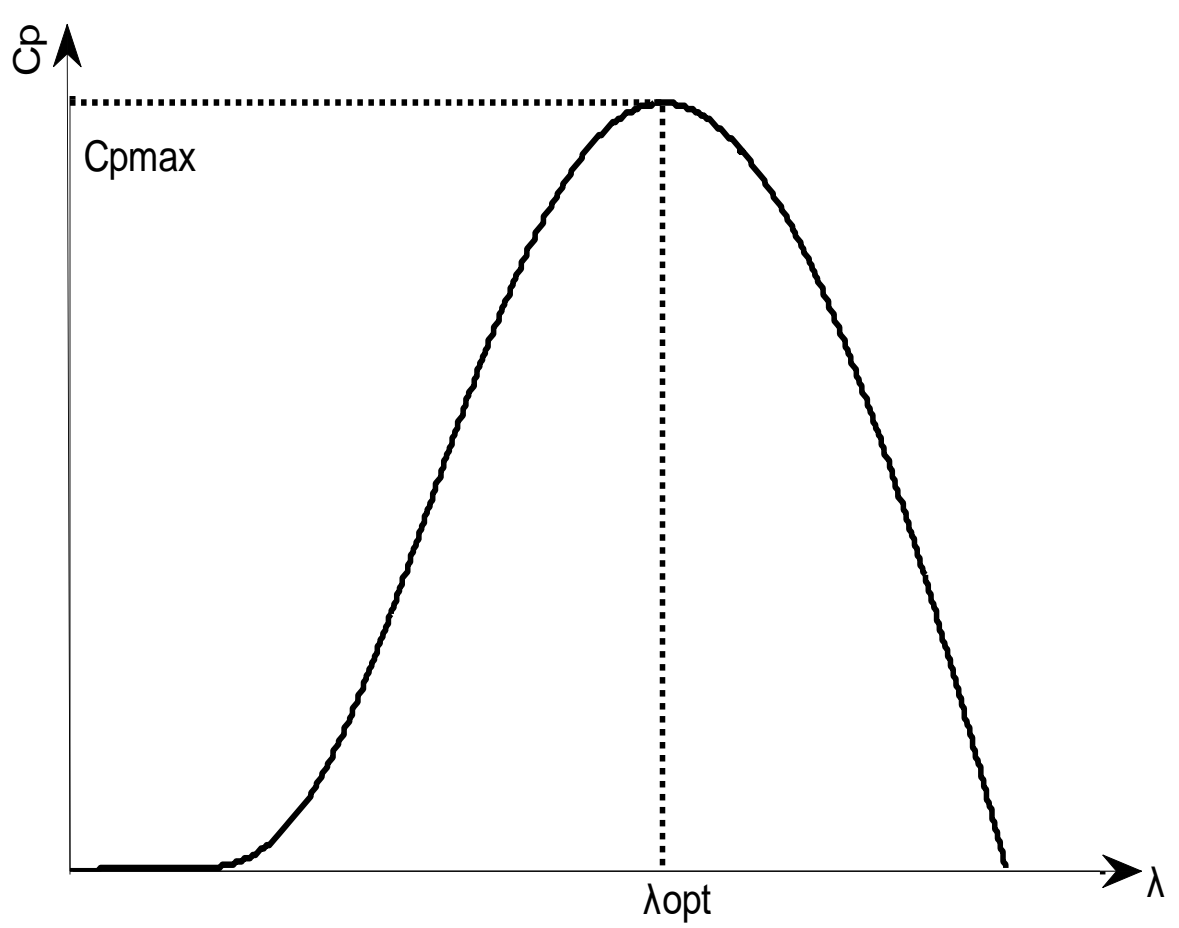

Figure 2. Coupling Relationship between $C_{\mathrm{p}}$ and $\lambda$

Hydraulic turbine is the device that transforms the kinetic energy carried by water into mechanical energy and then converts mechanical energy into electrical energy. The water from high place enters into hydraulic turbine, and then the kinetic energy contained in water is converted into rotational mechanical energy. The runner of hydraulic turbine is connected with generator rotor and drives the generator rotor to rotate together, and then the hydraulic turbine transforms its own rotating mechanical energy into electrical energy. The potential energy of water can be transformed into kinetic energy by equation (7).

$$
P_{0}=\rho v^{3} A / 2
$$

In equation (7), $\rho$ represents water density; ${ }^{v}$ represents water flow velocity; $A$ represents turbine impeller area.

The tip speed ratio of hydraulic turbine is shown as equation (8).

$$
\lambda=\frac{\omega R}{v}
$$

In equation (8), $R$ represents the radius of hydraulic turbine runner; ${ }^{\omega}$ represents the angular velocity of hydraulic turbine runner.

The energy utilization efficiency of water flow can be calculated by equation (9).

$$
C_{\mathrm{p}}=C_{\mathrm{p}}(\lambda, \beta)
$$

In equation (9), ${ }^{C_{\mathrm{p}}}$ represents the energy utilization efficiency of water flow, and ${ }^{C_{\mathrm{p}}}$ is a function of the tip speed ratio $\lambda$ and pitch angle $\beta$. In the case of the pitch angle and 
water flow velocity are unchanged, the tip speed ratio $\lambda$ is proportional to rotational speed. Therefore, the power of hydraulic turbine only depends on the runner rotational speed $\omega$. The power output of hydraulic turbine can be calculated by equation (10).

$$
P=C_{\mathrm{p}}(\omega) P_{0}
$$

The power and rotational speed relationship curve of hydraulic turbine is shown in Figure 3. It can be seen from Figure 3 that the power and rotational speed relationship curve is similar under different water flow velocity. At a certain water flow velocity, there is a certain maximum power point. Such as when the flow velocity is $u$, the rotational speed of the maximum power point is $\omega$.

\section{Operation Principles of Steam Turbine}

Steam turbine is the device that converts the heat energy of steam into kinetic energy, and then converts the kinetic energy into mechanical energy. The rotor of steam turbine is connected with generator rotor, and drives the generator rotor to rotate and converts mechanical energy into electrical energy. In order to improve the utilization efficiency of steam turbine, the internal control of steam turbine is hierarchical control according to the variation of pressure.

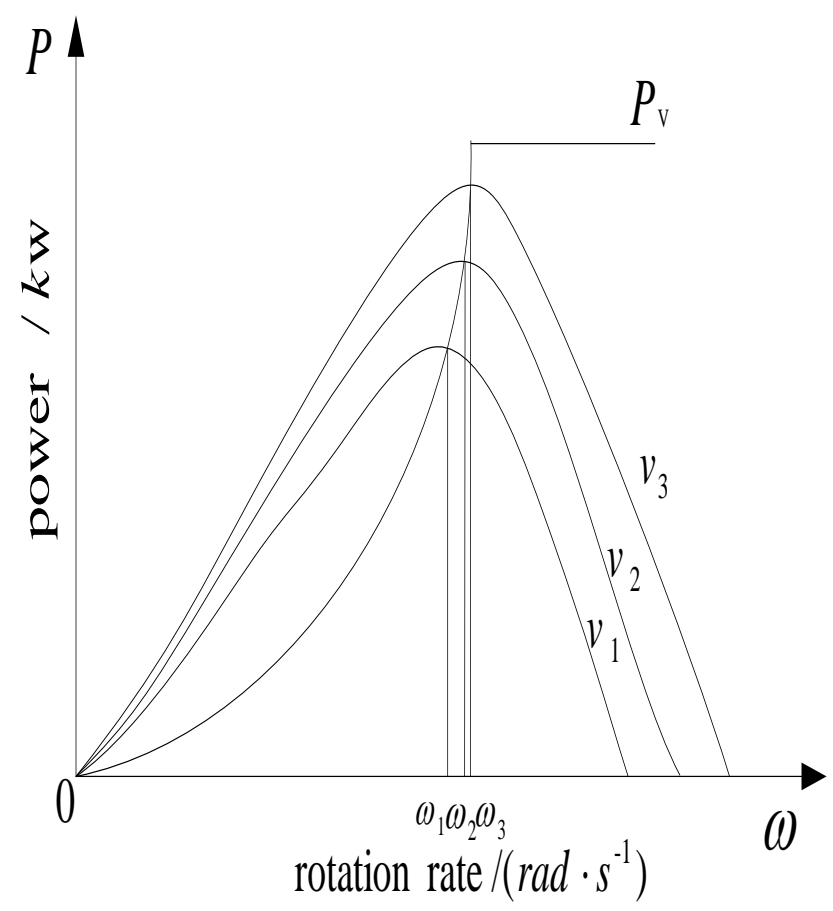

Figure 3. Relationship Curve of Power Output and Rotation Speed

For the multi-pressure steam turbine, the internal power $P_{i}$ can be calculated by equation (11).

$$
P_{i}=q_{m 0} \Delta H_{i}=q_{m 0} \Delta H_{t} \eta_{r i}
$$


In equation (11), ${ }^{q_{m 0}}$ represents the air intake; $\Delta H_{i}$ represents the effective internal enthalpy drop; $\eta_{r i}$ represents the internal efficiency, which is the ratio of the effective internal enthalpy drop $\Delta H_{i}$ to the ideal enthalpy drop $\Delta H_{t}$. Namely

$$
\eta_{r i}=\Delta H_{i} / \Delta H_{t}
$$

The effective power of steam turbine is equal to the mechanical power converted by the internal power, which can be calculated by equation (13).

$$
P_{e f i}=P_{i} \eta_{m}=q_{m 0} \Delta H_{t} \eta_{r i} \eta_{m}
$$

In equation(13), ${ }^{\eta_{m}}$ represents mechanical efficiency.

The electric power of steam turbine grade is equal to the electric power of effective power conversion, which can be calculated by equation (14).

$$
P_{e i}=P_{i} \eta_{m} \eta_{g}=q_{m 0} \Delta H_{t} \eta_{r i} \eta_{m} \eta_{g}
$$

In equation (14), ${ }^{\eta_{g}}$ represents power generation efficiency.

Steam turbine is generally composed of a number of grades, and the total power of steam turbine can be calculated by equation (15).

$$
P_{e}=\sum_{i=1}^{n} P_{e i}
$$

In equation (15), ${ }^{n}$ represents the number of steam turbine grades.

\section{Simulation Model Establishment}

In order to study the stability characteristics of power system with large-scale wind power, according to the above mathematical model, the hybrid power system model containing wind turbines, hydropower units and thermal power units is established in the paper. The hybrid power system model is shown in Figure 4. In Figure 4, G1 represents the hydropower units, the capacity of the hydropower units is 247.5MWA, the output voltage is $16.5 \mathrm{KV}$, and the power factor is $1 . \mathrm{G} 2$ represents the thermal power units, the capacity of the thermal power units is $192 \mathrm{MWA}$, the output voltage is $18 \mathrm{KV}$, and the power factor is 0.85 . G3 represents the wind turbines, the capacity of the wind turbines is $136.5 \mathrm{MWA}$, and the output voltage is $13.8 \mathrm{KV}$. The wind power capacity accounts for about $24 \%$ of the whole power system capacity, which can represent the phenomenon of large-scale wind power access to power system.

In the processes of calculation, the hydropower units G1 are selected as the balance node, the voltage amplitude of hydropower units is set to $1.04 \mathrm{pu}$, and the reference voltage phase angle of hydropower units is 0 degree. The wind turbines G3 and the thermal power units G2 are PV type node. the active power output of the wind turbines G3 is $1.63 \mathrm{pu}$, and the active power output of the thermal power units G2 is $0.85 \mathrm{pu}$, and the node voltage is $1.025 \mathrm{pu}$. The parameters of the whole system are shown in Table 1. 


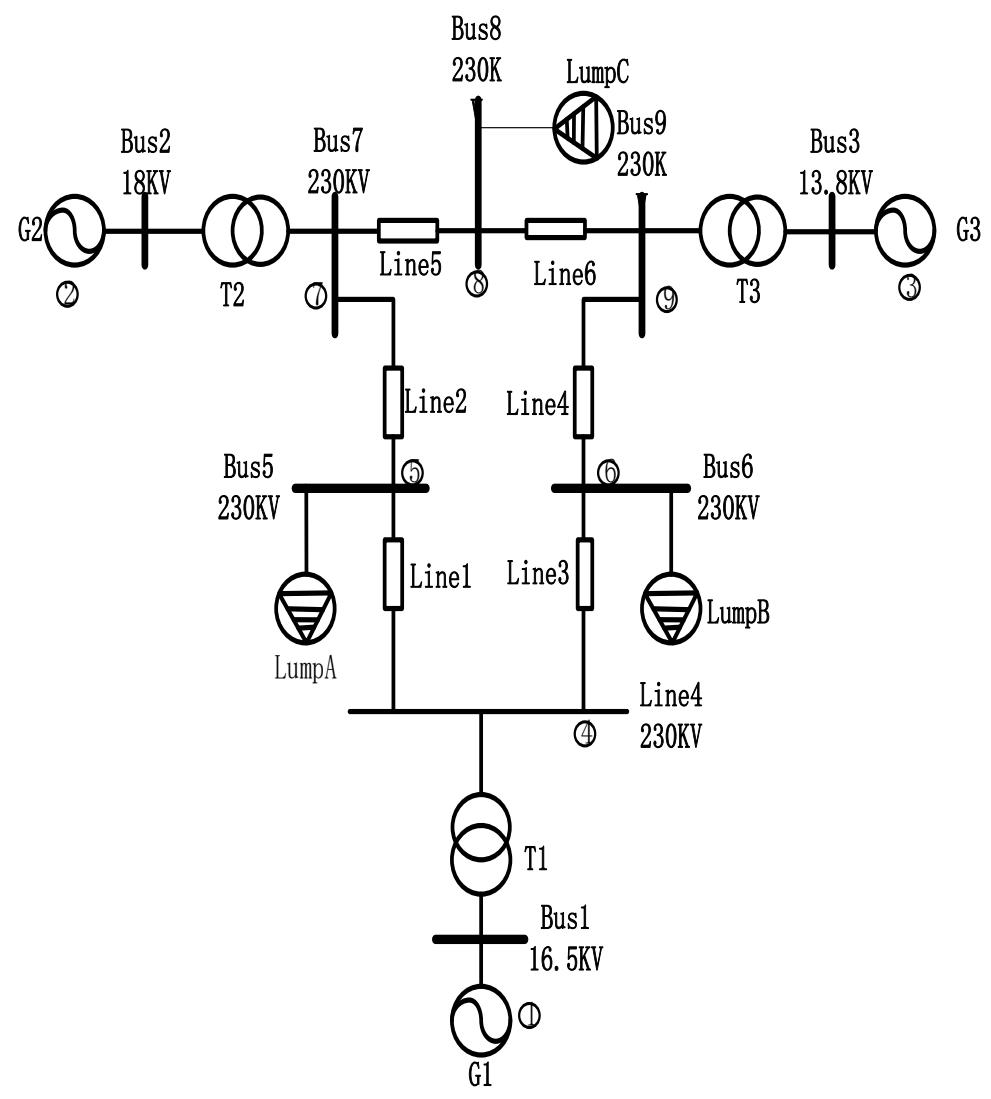

Figure 4. Structure of Multi-Source Hybrid Power Generation System

Table 1. Parameters of Multi-Source Hybrid Power Generation System

\begin{tabular}{|c|c|c|c|c|c|c|}
\hline \multirow[b]{2}{*}{ Circuitry } & \multirow[b]{2}{*}{ Serial number } & \multirow{2}{*}{$\begin{array}{l}\text { Line length } \\
\qquad(\mathrm{Km})\end{array}$} & \multicolumn{2}{|c|}{ Resistance } & \multicolumn{2}{|c|}{ Admittance } \\
\hline & & & $\mathrm{R}$ & $X$ & G & B \\
\hline \multirow{6}{*}{$\begin{array}{c}\text { Transmission } \\
\text { lines }\end{array}$} & 1 & 50 & 0.0100 & 0.0850 & 1.3652 & -11.6041 \\
\hline & 2 & 50 & 0.0170 & 0.0920 & 1.9422 & -10.5107 \\
\hline & 3 & 100 & 0.0320 & 0.1610 & 1.1876 & -5.9751 \\
\hline & 4 & 100 & 0.0390 & 0.1700 & 1.2820 & -5.5882 \\
\hline & 5 & 50 & 0.0085 & 0.0720 & 1.6171 & -13.6980 \\
\hline & 6 & 100 & 0.0119 & 0.1008 & 1.1551 & -9.7843 \\
\hline \multirow{3}{*}{ Generator } & 1 & & 0 & 0.1184 & 0 & -8.4459 \\
\hline & 2 & & 0 & 0.1823 & 0 & -5.4855 \\
\hline & 3 & & 0 & 0.2399 & 0 & -4.1684 \\
\hline \multirow{3}{*}{ Load } & A & & & & 1.2610 & -0.2634 \\
\hline & B & & & & 0.8777 & -0.0346 \\
\hline & C & & & & 0.9690 & -0.1601 \\
\hline
\end{tabular}




\section{Simulation and Analysis}

According to the structure and parameters of the multi-source hybrid electric power system, the system model is established and simulated. Figure 5 is the dynamic process characteristics of the wind turbines, hydropower units and thermal power units in the multi-source hybrid power system.

In Figure 5, between 0 to 10 seconds, the wind speed of wind turbines is $8 \mathrm{~m} / \mathrm{s}$, and the whole multi-source hybrid electric power system is in static balance state. In 10 seconds, the input wind speed changes from $8 \mathrm{~m} / \mathrm{s}$ to $6 \mathrm{~m} / \mathrm{s}$, and the power output of wind turbines reduces rapidly. In order to maintain the system power balance, the power output of hydropower units and thermal power units increases. However, because the power ramp rate of the hydropower units is faster than that of the thermal power units, the power output increase rate of the hydropower units is obviously faster than that of the thermal power units. Between 10 to 12 seconds, the power variation curve objectively reflects the dynamic change processes of the wind turbine power output, the hydropower units power output and the thermal power units power output.

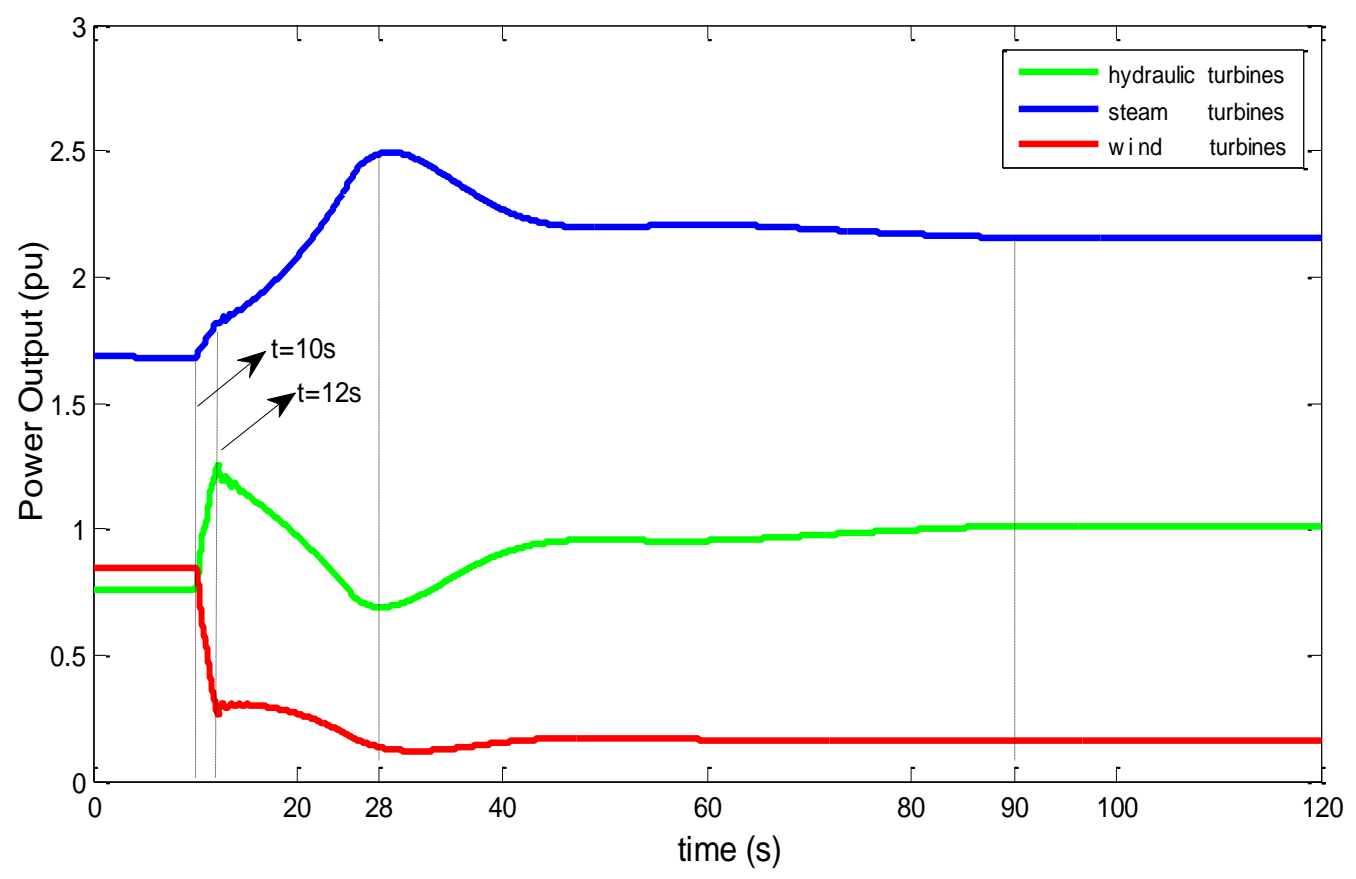

Figure 5. Dynamic Characteristics Curve of Actual Power Output

In 12 seconds, the total power output of wind turbines, hydropower units and thermal power units is equal to the load power. In this moment, the system is in a transient balance. After 12 seconds, due to the large time inertia of the steam turbines, the power output of the thermal power units will continue to increase. But, the power output increase rate of thermal power units will reduce. In order to maintain the system power balance, the power output of the wind turbines and hydropower units should reduce.

Since the power ramp rate of wind turbines is slower than that of hydropower units, resulting in the wind turbine power adjustment processes is slower than that of hydropower units. In Figure 5, during the period of 12 to 28 seconds, the power variation curves truly reflect the power output dynamic processes of wind turbines, hydropower units and thermal power units.

In 28 seconds, the power output of the thermal power units reaches the maximum value. After 28 seconds, the power output of the thermal power units will decrease. In order to maintain the stability of the multi-source hybrid electric power system, the power 
output of the wind turbines and hydropower units should increase. After 28 seconds, the wind turbines, hydropower units and thermal power units enter into the dynamic balance state. Until about 90 seconds, the whole multi-source hybrid power system reaches the static balance state.

The reactive power output curve of the wind turbines is shown in Figure 6. It can be seen from Figure 6 that the reactive power output of wind turbines begins to increase after 10 seconds. The reason for this phenomenon is due to the active power output of the wind turbines to reduce, in order to maintain the system power balance, the active power output of hydropower units has to be increased. However, the power factor of the hydropower units is 1 , which makes the system power factor increasing. In order to maintain the stability of the system power factor, the reactive power output of the wind turbines is increased. The dynamic change processes of reactive power output curve indirectly reflect the change processes of hydropower unit power output.

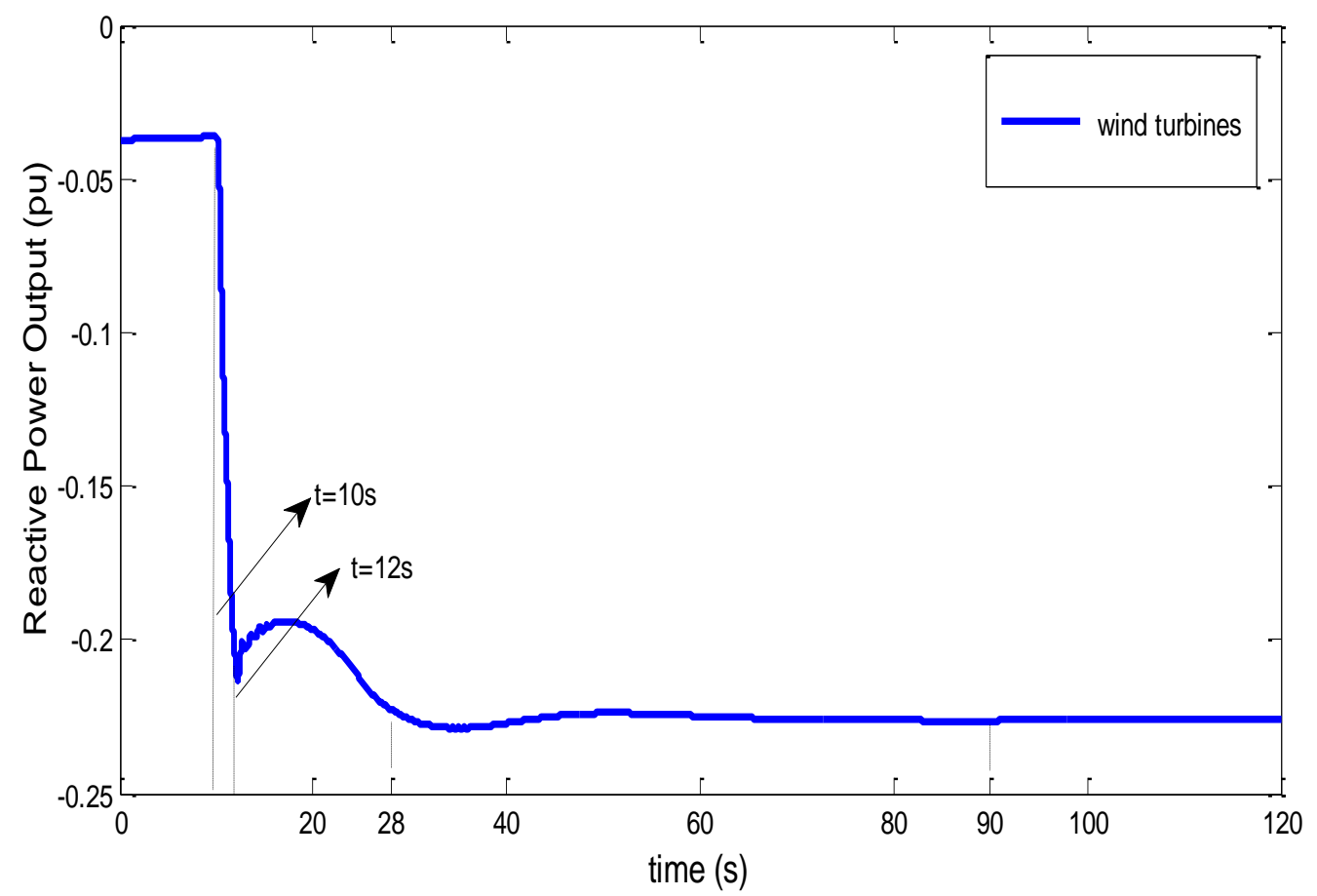

Figure 6. Reactive Power Output Dynamic Change Processes of Wind Turbines

The voltage dynamic processes of the wind turbines is shown in Figure 7. It can be seen from Figure 7 that the voltage of wind turbines accordingly increases because of the increase of reactive power output. The voltage curve dynamic processes directly reflect the change processes of wind turbines reactive power output. 


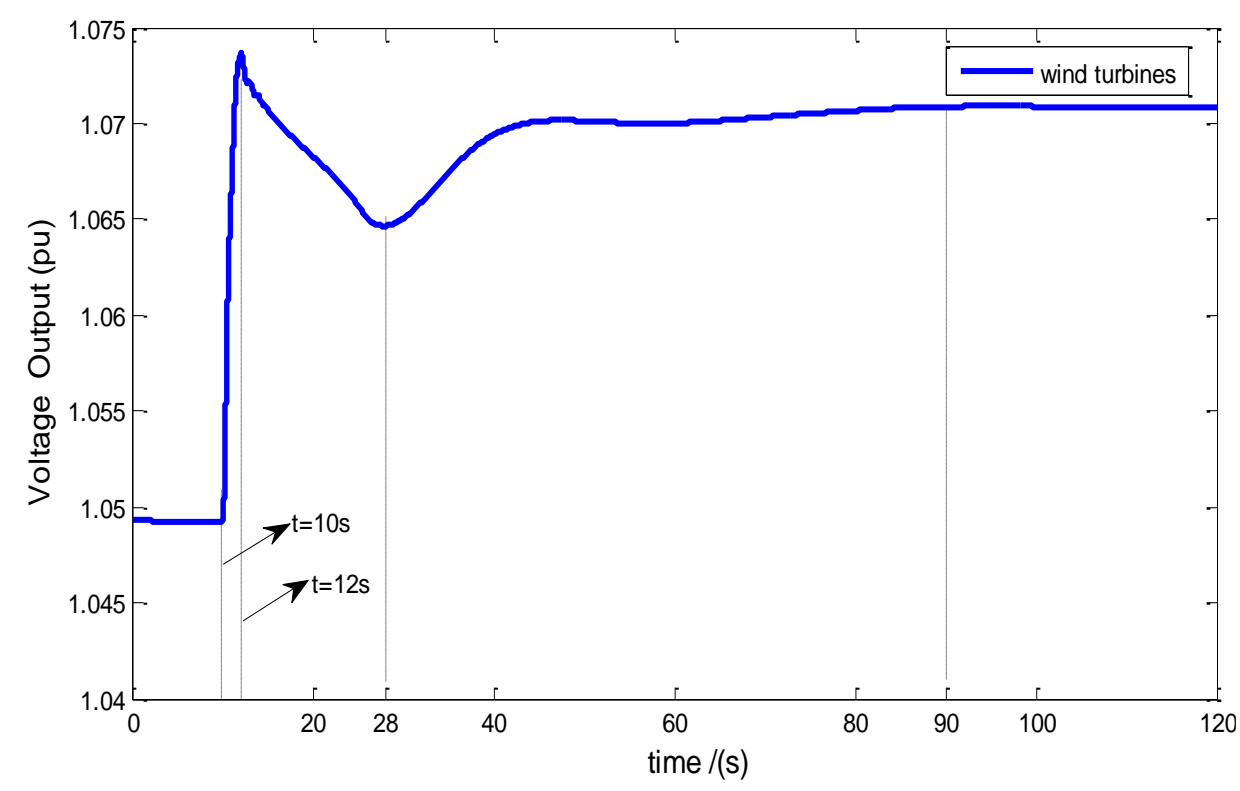

Figure 7. Voltage Output Dynamic Change Processes of Wind Turbines

The current output dynamic processes of wind turbines is shown in Figure 8. It can be seen from Figure 8 that the current output decreases after 10 seconds, the reason is that the wind speed changes from $8 \mathrm{~m} / \mathrm{s}$ to $6 \mathrm{~m} / \mathrm{s}$ in $10 \mathrm{~s}$, and the power output of wind turbines decreases after 10 seconds.

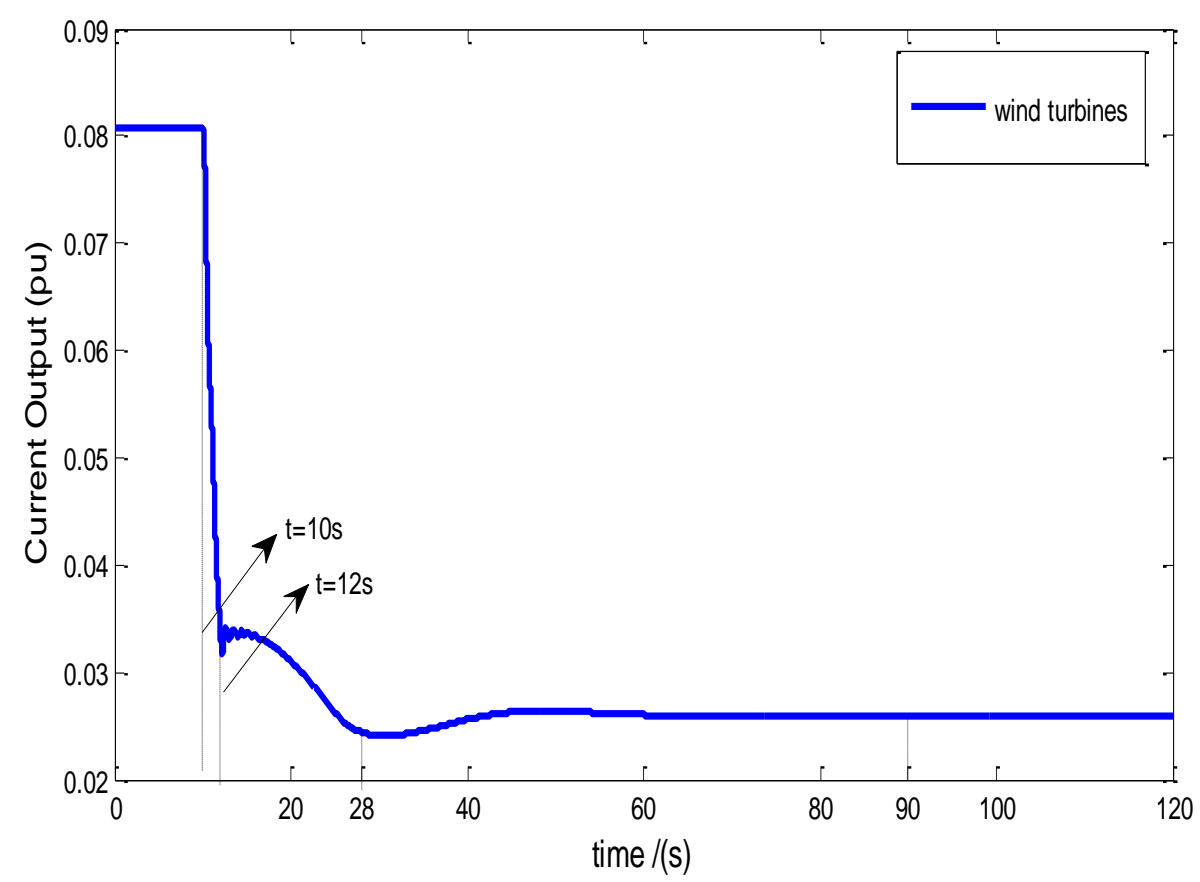

\section{Figure 8. Current Output Dynamic Change Processes of Wind Turbines}

It can be known from the above analysis that the model of the multi-source hybrid power system including wind turbines, hydropower units and thermal power units, can accurately describe the dynamic processes of the multi-source hybrid power system when the power output of wind turbines changes. 


\section{Conclusion}

The operation principles of wind turbines, hydraulic turbines and steam turbines are analyzed and the corresponding mathematical model are established. The multi-source hybrid electric power system including wind turbines, hydropower units and thermal power units is simulated and analyzed. The simulation results show that when the power output of wind turbines changes, the model of multi-source hybrid power system can accurately describe the dynamic characteristics of each component. Therefore, The multisource hybrid electric power system established in the paper can provide support for the study on the stability of power system with large-scale wind power.

\section{Acknowledgments}

This study has been funded by Key Projects of Science and Technology in Henan Province (152102210117), Research Cooperation Project of Henan Province (162107000049), and Key projects of Higher Education in Henan Province (70556). Moreover, the authors wish to thank these people who have given a lot of help for the study, but their names are not listed in the paper.

\section{References}

[1] M. P. D. Arce, E. Sauma, J. Contreras, R. S. J. Tol and J. P. Weyant, "Renewable Energy Policy Performance in Reducing CO2 Emissions", Energy Economics, vol. 54, (2016), pp. 272-280.

[2] N. Scarlat, J. F. Dallemand, F. Monforti-Ferrario, M. Banja and V. Motola, "Renewable Energy Policy Framework and Bioenergy Contribution in the European Union-An Overview from National Renewable Energy Action Plans and Progress Reports", Renewable and Sustainable Energy Reviews, vol. 51, no. 6, (2015), pp. 969-985.

[3] B. Fais, N. Sabio and N. Strachan, "The Critical Role of the Industrial Sector in Reaching Long-term Emission Reduction, Energy Efficiency and Renewable Targets", Applied Energy, vol. 162, (2016), pp. 699-712.

[4] A. P. Mathews, "Renewable Energy Technologies: Panacea for World Energy Security and Climate Change", Procedia Computer Science, vol. 32, (2014), pp. 731-737.

[5] F. Baghdadi, K. Mohammedi, S. Diaf and O. Behar, "Feasibility Study and Energy Conversion Analysis of Stand-alone Hybrid Renewable Energy System", Energy Conversion and Management, vol. 105, (2015), pp. 471-479.

[6] C. Brandoni, M. Renzi, F. Caresana and F. Polonara, "Simulation of Hybrid Renewable Microgeneration Systems for Variable Electricity Conversion Analysis of Stand-alone Hybrid Prices", Applied Thermal Engineering, vol. 71, no. 2, (2014), pp. 667-676.

[7] K. K. Shah, A. S. Mundada and J. M. Pearce, "Performance of U.S. Hybrid Distributed Energy Systems: Solar Photovoltaic, Battery and Combined Heat and Power", Energy Conversion \& Management, vol. 105, (2015), pp. 71-80.

[8] V. Khare, S. Nema and P. Baredar, "Solar-wind Hybrid Renewable Energy System: A Review", Renewable and Sustainable Energy Reviews, vol. 58, (2016), pp. 23-33.

[9] Y. W. Ma, P. Yang, H. X. Guo and J. Wu, "Power Planning of Renewable Energy Distributed Generation System Including Light-wind-methane”, Power Grid Technology, vol. 36, no. 9, (2012), pp. 9-14.

[10] L. Y. Li, W. L. Wu and D. T. Shen, "Modeling and Research of Hybrid Power Generation System with Wind-light-water", East China Electric Power, vol.40, (2012), pp. 1157-1160.

[11] C. Li, Y. Zheng and Y. Lu, "Modeling and Optimization of Independent Hybrid Power Generation System Including Wind-light-storage", Journal of Irrigation and Drainage Engineering, vol. 32, (2014), pp. 64-69.

[12] G. T. Xue, Y. Zhang and D. K. Zhu, "Power Control and Energy Management Strategy of Hybrid Power System”, East China Electric Power, vol. 40, (2012), pp. 1749-1753. 


\section{Author}

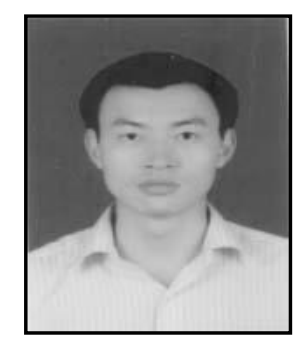

Gu Bo, Received the Master degree in North China University of Water Resources and Electric Power in 2006, received the Doctor degree in North China Electric Power University in 2016. Currently, he is a lecturer at North China University of Water Resources and Electric power. His interests are the wind power technology, the hydraulic power generation technology. 